\title{
New trends in ACL research
}

\author{
Volker Musahl • Roland Becker • Freddie H. Fu • \\ Jon Karlsson
}

Published online: 27 September 2011

(C) Springer-Verlag 2011

ACL research has driven ACL surgery and, through extensive work over the past 10 years, clearly established "anatomic ACL reconstruction". At the recent Panther Global Summit (Pittsburgh, PA, USA, August 25-27, 2011), 24/28 (85\%) experts utilized anatomic techniques for ACL reconstruction. In contrast, $70 \%$ of a global expert panel in the year 2000 preferred the transtibial technique for ACL reconstruction [8].

While the past 10 years in ACL research were dedicated to the rediscovery of double-bundle ACL reconstruction, the more recent past research is dedicated to identifying criteria for anatomic single bundle versus anatomic doublebundle ACL reconstruction. An important part of the rediscovery is the treatment algorithm for anatomic ACL reconstruction by Fu et al. [14]. The most commonly listed indications for double-bundle ACL reconstructions are (1) large insertion sites $(>18 \mathrm{~mm}$ tibial ACL anteroposterior diameter), (2) wide notch width (>12 mm), (3) high-grade pivot shift, and (4) revision ACL reconstruction. There are established contraindications for double-bundle ACL reconstruction, such as (1) multi-ligament injuries, (2) open physes, (3) degenerative OA, (4) small insertion sites $(<12 \mathrm{~mm}$ tibial anterior-posterior diameter), and (5) small

V. Musahl $(\bowtie) \cdot$ F. H. Fu

Department of Orthopaedic Surgery,

University of Pittsburgh Medical Center, Pittsburgh, PA, USA

e-mail: musahlv@upmc.edu

R. Becker

Department of Orthopaedic and Traumatology, City Hospital Brandenburg, Hochstrasse 29, 14770 Brandenburg/Havel, Germany

J. Karlsson

Department of Orthopaedics, Sahlgrenska University Hospital,

Gothenburg, Sweden notch width $(<12 \mathrm{~mm})$. It is noteworthy that there are no contraindications for anatomic ACL reconstruction.

A considerable amount of research is being done in the field of ACL remnant preservation. In contrast to the 1990s, when non-anatomic guides were most commonly used for tunnel placement, it is now widely recognized that anatomic ACL reconstruction demands adequate identification of anatomical landmarks, such as the femoral ridges and the footprints on the tibia and femur, respectively [6, 15]. Preservation of the native ACL remnants is furthermore shown to enhance biomechanical knee stability [11], as well as provides mechanoreceptors that potentially improve proprioceptive function following ACL reconstruction [1]. At the recent Panther Global Summit, 20/28 $(68 \%)$ experts preserve remnants during ACL reconstruction surgery.

Musculoskeletal imaging has improved in many ways. MRI is not only used for diagnosis and pre-operative planning purposes, but it can be used post-operatively for the assessment of ACL graft healing and development of osteoarthritis. MRI can also assist in accurately identifying ACL injury patterns [2, 13]. The utilization of post-operative radiographs is still the most common modality to assess adequate tunnel placement. However, 3-D CT is superior to radiographs and more clearly reflects the intraoperative perspective of the arthroscopic surgeon. 3-D CT provides a critical assessment of accurate tunnel placement $[7,10]$.

There is, and has been, much hype about biological enhancements for ACL healing and/or reconstruction. However, hardly any treatments have made a clinical impact beyond in vitro- and animal research. One of the few approved treatments is growth factor therapy in the form of autologous fibrin clots or platelet-rich plasma (PRP). A fibrin clot between the two grafts for double- 
bundle ACL reconstruction can enhance healing in a large animal model [9]. PRP was shown to enhance ACL cell viability and function in vitro [5]. Even "ACL healing" and primary repair of the injured ACL are being explored. Recent research has employed PRP combined with collagen to modulate growth factor release from platelets to stimulate ACL healing [16].

Female ACL research is still evolving. We know that the risk of an ACL injury is up to 10 times higher in women compared to men. We know there are risk factors, such as anatomic factors (e.g., morphology, notch width, lower extremity valgus), hormonal factors, and biomechanical factors (e.g., hamstring weakness, jump-land pattern). Could there be a genetic predisposition for higher ACL injury rates for female athletes? A specific genetic risk factor (CC genotype of BstUI restriction fragment length polymorphism within the COL5A1 gene) was found to be associated with the risk of ACL ruptures in female athletes. [12].

Criteria for returning athletes to sport following ACL reconstruction surgery have not changed; (1) time from injury, (2) absence of pain/swelling, (3) full ROM, (4) restored ligamentous laxity, (5) quadriceps strength, and (6) one-leg hop test. However, at the recent Panther Global Summit, $70 \%$ of the experts consider graft healing in making return to play decisions. From the literature of early graft failure following allograft ACL reconstruction, we have learnt that time from surgery may be the most important factor. In the future, MRI may provide valuable information on healing graft tissue.

Does ACL injury inevitably result in osteoarthritis? New research strategies are investigating this question, involving MRI, functional joint assessment with dynamic stereo radiography (DSX), and joint fluid marker analysis. Utilizing DSX, it is demonstrated that knee joint kinematics of the ACL reconstructed knee are significantly different from those of uninjured controls during functional tasks of single-legged hop landing. This may in turn contribute to long-term joint degeneration [4]. The 2010 AOSSM/NIH u-13 post-joint injury osteoarthritis conference concluded that there is a strong consensus for approaching the development of disease-modifying treatments for osteoarthritis through study of "pre-osteoarthritic" cohorts [3].

In summary, we are now more anatomic than ever, which includes the study, preservation, and reconstruction of ACL footprint anatomy. "Dare" to use advanced postoperative imaging to enhance your own ACL reconstruction technique and ultimately improve patient outcome. Biological treatments are still evolving, yet a simple and cheap fibrin clot may deliver desired growth factors to healing sites. We expect lots of new data from studies that investigate bony morphology as well as genetic predisposition, and its influence on the prevalence of instability and
ACL injury. We also need to better understand what happens after the ACL reconstruction, the patient-related outcomes are vital. And we must always remember that the patient is the one who can best judge the functional status of the knee. It is also of great importance to be able to better evaluate the surgical techniques that are used today. Standardized techniques (scoring systems) that can assess and compare different surgical techniques are evolving.

The ultimate goal of ACL reconstruction surgery is to prevent the development of osteoarthritis. This may involve measures, such as anatomic surgery, possibly disease-modifying treatments, and longer time to return to play following ACL reconstruction surgery to allow for adequate healing of the reconstructed ACL.

Conflict of interest The authors declare that they have no conflict of interest.

\section{References}

1. Bali K, Dhillon MS, Vasistha RK, Kakkar N, Chana R, Prabhakar S (2011) Efficacy of immunohistological methods in detecting functionally viable mechanoreceptors in the remnant stumps of injured anterior cruciate ligaments and its clinical importance. Knee Surg Sports Traumatol Arthrosc. doi:10.1007/s00167-0111526-9

2. Casagranda BU, Maxwell NJ, Kavanagh EC, Towers JD, Shen W, Fu FH (2009) Normal appearance and complications of double-bundle and selective-bundle anterior cruciate ligament reconstructions using optimal MRI techniques. AJR Am J Roentgenol 192:1407-1415

3. Chu CR, Beynnon BD, Buckwalter JA, Garrett WE Jr, Katz JN, Rodeo SA, Spindler KP, Stanton RA (2011) Closing the gap between bench and bedside research for early arthritis therapies (EARTH): report from the AOSSM/NIH U-13 Post-Joint Injury Osteoarthritis Conference II. Am J Sports Med 39:15691578

4. Deneweth JM, Bey MJ, McLean SG, Lock TR, Kolowich PA, Tashman S (2010) Tibiofemoral joint kinematics of the anterior cruciate ligament-reconstructed knee during a single-legged hop landing. Am J Sports Med 38:1820-1828

5. Fallouh L, Nakagawa K, Sasho T, Arai M, Kitahara S, Wada Y, Moriya H, Takahashi K (2010) Effects of autologous platelet-rich plasma on cell viability and collagen synthesis in injured human anterior cruciate ligament. J Bone Joint Surg Am 92:2909-2916

6. Ferretti M, Ekdahl M, Shen W, Fu FH (2007) Osseous landmarks of the femoral attachment of the anterior cruciate ligament: an anatomic study. Arthroscopy 23:1218-1225

7. Forsythe B, Kopf S, Wong AK, Martins CA, Anderst W, Tashman S, Fu FH (2010) The location of femoral and tibial tunnels in anatomic double-bundle anterior cruciate ligament reconstruction analyzed by three-dimensional computed tomography models. J Bone Joint Surg Am 92:1418-1426

8. Harner CD, Fu FH, Irrgang JJ, Vogrin TM (2001) Anterior and posterior cruciate ligament reconstruction in the new millennium: a global perspective. Knee Surg Sports Traumatol Arthrosc 9:330-336

9. Illingworth K, Musahl V, Lorenz S, Fu FH (2010) The use of fibrin clot in the knee. Op Technol Orthop 20:90-97 
10. Kopf S, Forsythe B, Wong AK, Tashman S, Anderst W, Irrgang JJ, Fu FH (2010) Nonanatomic tunnel position in traditional transtibial single-bundle anterior cruciate ligament reconstruction evaluated by three-dimensional computed tomography. J Bone Joint Surg Am 92:1427-1431

11. Nakamae A, Ochi M, Deie M, Adachi N, Kanaya A, Nishimori M, Nakasa T (2010) Biomechanical function of anterior cruciate ligament remnants: how long do they contribute to knee stability after injury in patients with complete tears? Arthroscopy 26:1577-1585

12. Posthumus M, September AV, O'Cuinneagain D, van der Merwe W, Schwellnus MP, Collins M (2009) The COL5A1 gene is associated with increased risk of anterior cruciate ligament ruptures in female participants. Am J Sports Med 37:2234-2240

13. Van Dyck P, De Smet E, Veryser J, Lambrecht V, Gielen JL, Vanhoenacker FM, Dossche L, Parizel PM (2011) Partial tear of the anterior cruciate ligament of the knee: injury patterns on MR imaging. Knee Surg Sports Traumatol Arthrosc. doi:10.1007/ s00167-011-1617-7

14. van Eck CF, Lesniak BP, Schreiber VM, Fu FH (2010) Anatomic single- and double-bundle anterior cruciate ligament reconstruction flowchart. Arthroscopy 26:258-268

15. van Eck CF, Schreiber VM, Mejia HA, Samuelsson K, van Dijk CN, Karlsson J, Fu FH (2010) "Anatomic" anterior cruciate ligament reconstruction: a systematic review of surgical techniques and reporting of surgical data. Arthroscopy 26(9):S2-S12

16. Vavken P, Saad FA, Fleming BC, Murray MM (2011) VEGF receptor mRNA expression by ACL fibroblasts is associated with functional healing of the ACL. Knee Surg Sports Traumatol Arthrosc 19:1675-1682 